\title{
A Simple and Fast Method for Magnetic Solid Phase Extraction of Ochratoxin A
}

\author{
Azam Sargazi, ${ }^{a}$ Amin Aliabadi, ${ }^{a, b}$ Ali Rahdari, ${ }^{a, b}$ Samin Allahdini-Hesaroiyeh, ${ }^{a, b}$ \\ Massoud Nejati-Yazdinejad ${ }^{c}$ and Mostafa Heidari Majd ${ }^{*, a}$
}

\author{
${ }^{a}$ Faculty of Pharmacy and ${ }^{b}$ Student Research Committee, Zabol University of Medical Sciences, Zabol, Iran \\ 'Department of Chemistry, Faculty of Sciences, University of Zabol, Zabol, Iran
}

\begin{abstract}
We report on the synthesis of dopamine loaded magnetic nanoparticles (MNPs) for new, simple, fast and repeatable extraction of ochratoxin A from different solvents and milk without utilizing immunoaffinity columns and even high-tech devices. To this end, $\mathrm{Fe}_{3} \mathrm{O}_{4}$ nanoparticles (NPs) were synthesized using thermal decomposition reaction and dopamine (DPA) was then conjugated with $\mathrm{Fe}_{3} \mathrm{O}_{4}$ nanoparticles (NPs) to form $\mathrm{Fe}_{3} \mathrm{O}_{4}$-DPA NPs. Dynamic light scattering, field emission scanning electron microscopy and transmission electron microscopy revealed an average size of about $15 \mathrm{~nm}$ for $\mathrm{Fe}_{3} \mathrm{O}_{4}$-DPA NPs. Moreover, zeta potential measurement and vibrating sample magnetometer confirmed positively charged $(16.8 \mathrm{mV})$ and superparamagnetic behavior of MNPs, which are effective factors for a good adsorbent in the extraction. Various solvents and different effective parameters were measured until acetonitrile:methanol was selected as the best extraction solvent. In addition, based on the $\mathrm{pH}$-partition theory, with changes in $\mathrm{pH}$, we were able to increase and enhance the extraction rate to $94 \%$. Moreover, the ability of $\mathrm{Fe}_{3} \mathrm{O}_{4}$-DPA NPs in solid phase extraction of ochratoxin A from spiked milk was evaluated. The recovery rate for extraction of OTA from milk was $68 \%$.
\end{abstract}

Keywords: ochratoxin A, magnetic nanoparticles, HPLC, solid phase extraction, fluorescence spectroscopy

\section{Introduction}

Mycotoxins are secondary fungal metabolites that can contaminate agricultural commodities and animal feeds. ${ }^{1}$ In great variety of foods, some species of Aspergillus fungi produce a carcinogenic metabolite called ochratoxin A (OTA). ${ }^{2}$

Ochratoxin A is a stable molecule that resists degradation in acidic conditions, food processing and also blood serum with 35 days half-life. It can cause nephrotoxic, hepatotoxic, neurotoxic, teratogenic and immunotoxic diseases in humans..$^{1-4}$ Several methods for laboratory analysis and detection of ochratoxin A in food samples such as thin layer chromatography (TLC), high-performance liquid chromatography (HPLC), gas chromatographymass spectrometry (GC-MS), fluorescence polarization immunoassays, capillary electrophoresis (CE), enzymelinked immunosorbent assay (ELISA) and fluorescent and surface plasmon resonance immunosensors have been reported. ${ }^{1,2,5}$ The most frequently used method for the

*e-mail: mostafamajd@live.com,mhmajd@zbmu.ac.ir determination of OTA in grains and many other foodstuffs is extraction and clean up via immunoaffinity column (IAC) before employing the HPLC. ${ }^{6-8}$ In all validated methods for the detection of OTA based on IAC, solvents were utilized for extraction of OTA from real samples. Thereafter, these solvents were passed through the immunoaffinity column containing antibodies specific for OTA. ${ }^{9}$ However, this method has some disadvantages which reduce its efficiency; the contamination of immunoaffinity columns with the ethyl ester of ochratoxin A is one of such disadvantages. ${ }^{7}$ Accordingly, we intend to use magnetic solid phase extraction (MSPE) as an alternative for IAC. So, it is necessary to find suitable solvents for extraction and also determine the ability of magnetic nanoparticles to provide acceptable interaction with OTA.

Over the past decade, solid phase extraction (SPE) of organic and inorganic species has been developed as a fast alternative method. ${ }^{10}$ Meanwhile, magnetic solid phase extraction has been introduced for extraction of ochratoxin A from food and agriculture products. ${ }^{11,12}$ Due to the physiological form (di anionic, OTA $^{2-}$ ) and hydrophobic moieties of ochratoxin A, magnetic nanoparticles (MNPs) 
are the best choice for adsorption of OTA on their modified surface. ${ }^{6,13}$ Low toxicity, simple preparation and low price are some of the benefits of MNPs which guarantee high extraction efficiency. Moreover, reuse of MNPs is another advantage for MSPE method, because reused immunoaffinity columns give some problems for analysis. ${ }^{7}$ Nevertheless, unmodified MNPs have high tendency to agglomerate due to their high surface energy, but MNPs can be grafted with functional groups for further stability in fluids. ${ }^{14}$

Dopamine (DPA) as an anchoring agent could modify the surface of MNPs ${ }^{15}$ and provide so much stability for MNPs with amine-end terminated surface. ${ }^{16}$ In the present study, for the first time, dopamine loaded MNPs were used as electrostatic sorbents in magnetic solid phase extraction to separate ochratoxin A from different solvents and milk without utilizing immunoaffinity columns and even high-tech devices.

\section{Experimental}

Materials

Iron(III) acetylacetonate $\left[\mathrm{Fe}(\mathrm{acac})_{3}\right]$, benzyl ether, triethylamine and standard solution of ochratoxin A (OTA) was purchased from Merck (Hohenbrunn, Germany). Oleylamine and dopamine hydrobromide (DPA) was supplied from Sigma-Aldrich (Steinheim, Germany). All HPLC grade and analytical grade solvents were delivered from Merck (Gernsheim, Germany).

\section{Synthesis of $\mathrm{Fe}_{3} \mathrm{O}_{4}$-DPA magnetic nanoparticles}

$\mathrm{Fe}_{3} \mathrm{O}_{4}$ magnetic nanoparticles were synthesized via thermal decomposition reaction as described previously. ${ }^{17,18}$ In the next step, $\mathrm{Fe}_{3} \mathrm{O}_{4}(0.2 \mathrm{~g}, 0.86 \mathrm{mmol})$ was dispersed in $8 \mathrm{~mL}$ dichloromethane. Dopamine hydrobromide $(0.5 \mathrm{~g}$, $2.14 \mathrm{mmol}$ ) was added to the solution and stirred overnight under argon blanket at $25{ }^{\circ} \mathrm{C}$. Thereafter, solutions were sonicated for $15 \mathrm{~min}$ and $\mathrm{Fe}_{3} \mathrm{O}_{4}$-DPA (Figure 1A) was precipitated utilizing hexane. The yield was $86.5 \%$.

\section{Characterization of modified $\mathrm{Fe}_{3} \mathrm{O}_{4}$}

The surface modifications of MNPs were validated by Fourier transform infrared spectroscopy (FTIR) using Shimadzu IR PRESTIGE 21 spectrophotometer (Shimadzu

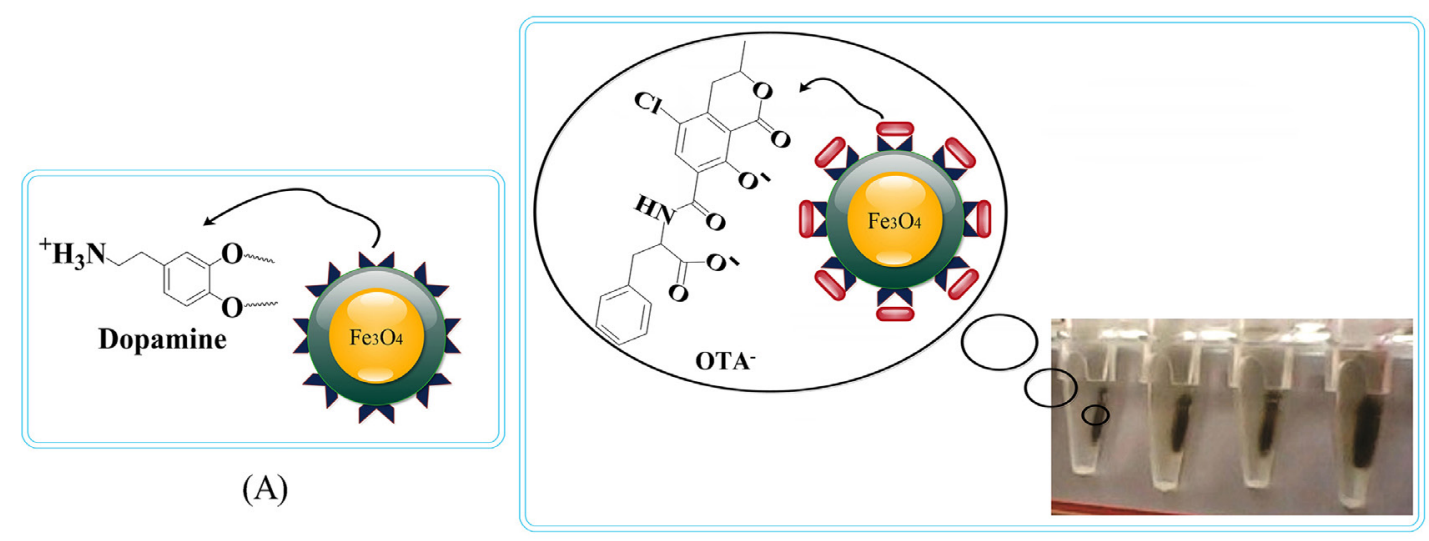

(B)

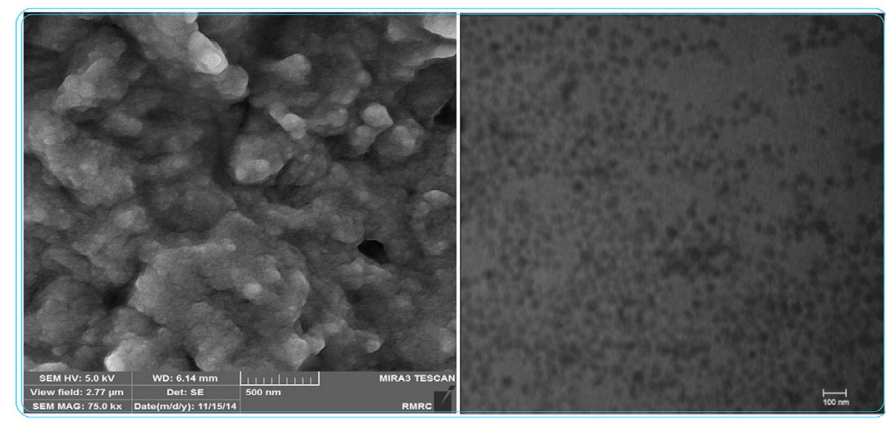

(C)

(D)

Figure 1. Schematic modification, separation ability, morphology and size of the engineered MNPs. (A) Dopamine conjugated MNPs; (B) successful separation of $\mathrm{Fe}_{3} \mathrm{O}_{4}$-DPA NPs (adsorbents containing OTA) from supernatant; (C) FESEM of $\mathrm{Fe}_{3} \mathrm{O}_{4}$-DPA NPs with an average size of ca. $15 \mathrm{~nm}$; (D) TEM of $\mathrm{Fe}_{3} \mathrm{O}_{4}$-DPA NPs. 
Scientific Instruments, Tokyo, Japan). The magnetization measurements of the $\mathrm{Fe}_{3} \mathrm{O}_{4} \mathrm{NPs}$ and $\mathrm{Fe}_{3} \mathrm{O}_{4}$-DPA NPs were carried out utilizing vibrating sample magnetometer (VSM) (Meghnatis Daghigh Kavir Co, Tehran, Iran). The size and morphological studies of MNPs were carried out using field emission scanning electron microscopy (FESEM) (Mira 3-XMU, Brno, Czech Republic) and transmission electron microscopy (TEM) (LEO 906, Carl Zeiss, Oberkochen, Germany).

Dynamic light scattering (DLS) by Nanotrac Wave ${ }^{\mathrm{TM}}$ (Microtrac, San Diego, CA, USA) also proved the size of the engineered MNPs. ${ }^{19}$ MNPs were specifically analyzed in terms of the hydrodynamic radius at a range of 0.8 to $6500 \mathrm{~nm}$ and zeta potential from -125 to $+125 \mathrm{mV}$. The size of MNPs was calculated by fitting the data to a polydispersed model using the Dynamics software version 5.26 (Microtrac, San Diego, CA, USA).

\section{Sample solutions}

Several sample solutions containing $10 \mathrm{ng} \mathrm{mL}^{-1}$ of ochratoxin A were prepared in micro tubes by variable solvents (all volumes are $2 \mathrm{~mL}$ ). After filtering through $0.2 \mu \mathrm{m}$ membrane, $100 \mu \mathrm{L}$ of samples were injected into the HPLC for analysis (pre-extraction analysis). In addition, different desorption solvents were utilized.

\section{Evaluation of the ability of MNPs in extraction of ochratoxin A from solvents}

In each of the above sample solutions $(2 \mathrm{~mL}), 30 \mathrm{ng}$ of $\mathrm{Fe}_{3} \mathrm{O}_{4}$-DPA magnetic nanoparticles were added. The mixture was shaken on a shaker instrument (three different times: 10 , $20,30 \mathrm{~min}$ ). Thereafter, magnetic adsorbents were collected utilizing the Invitrogen magnetic bead separation system "DYNAL". Figure 1B illustrates the successful separation of MNPs from solvents. Before desorption of toxins from magnetic adsorbents, $100 \mu \mathrm{L}$ of supernatants were injected into HPLC for analysis (extraction analysis). Finally, $2 \mathrm{~mL}$ of desorption solvents were added into collected MNPs. The mixture was shaken for three different times (10, 20,30 min). After this stage, magnetic adsorbents were re-collected using the Invitrogen magnetic bead separation system and $100 \mu \mathrm{L}$ of supernatants were injected into HPLC for analysis (post-extraction analysis).

Instrumentation

The HPLC system employed for OTA determination was a CECIL system with a Shimadzu fluorescence detector (RF-10AXL). The performance column was a reverse- phase $125 \times 4.6 \mathrm{~mm}$ (PerfectSil Target ODS-3 $3 \mu \mathrm{m})$. The mobile phase consisted of acetonitrile with $49.5 \%(\mathrm{v} / \mathrm{v})$, water with $49.5 \%(\mathrm{v} / \mathrm{v})$ and acetic acid $1 \%(\mathrm{v} / \mathrm{v})$ delivered at $1.5 \mathrm{~mL} \mathrm{~min}^{-1}$. Excitation and emission wavelengths were at 337 and $477 \mathrm{~nm}$, respectively (retention time: $2.5-3.5 \mathrm{~min}$ ).

\section{Fluorescence spectroscopy}

To complete the investigation, analysis of OTA was also performed employing a SHIMADZU RF-5301 $1_{\mathrm{PC}}$ fluorescence spectrophotometer at room temperature. The fluorescence spectra of OTA were taken in the best extraction solvent obtained from HPLC results at 334 and $451 \mathrm{~nm}$ excitation and emission wavelength, respectively. ${ }^{20}$

Separately, 30 ng of $\mathrm{Fe}_{3} \mathrm{O}_{4}$-DPA magnetic nanoparticles were added to a micro tube containing $10 \mathrm{ng} \mathrm{mL}^{-1}$ of ochratoxin A. The mixture was shaken for $10 \mathrm{~min}$ and magnetic adsorbents were collected utilizing the Invitrogen magnetic bead separation system "DYNAL". Finally, extraction percentage of OTA by MNPs was calculated using fluorescence intensity of supernatant.

\section{Magnetic solid phase extraction of ochratoxin A from real} sample

The magnetic solid phase extraction (MSPE) procedure was done as follows: liquid milk samples $(5.0 \pm 0.5 \mathrm{~mL})$ were added to $15 \mathrm{~mL}$ Falcon tubes and then volumes were elevated to $10 \mathrm{~mL}$ by the acetonitrile: methanol $(80: 20 \mathrm{v} / \mathrm{v})$ with $\mathrm{pH}=5$. Solutions were centrifuged at $5000 \times \mathrm{g}$ for $20 \mathrm{~min}$ to isolate fat layer and aqueous supernatant. Exactly 1, 5, 10 and $20 \mathrm{ng}$ of ochratoxin A were added to each Falcon tube containing supernatant and then $30 \mathrm{ng}$ of $\mathrm{Fe}_{3} \mathrm{O}_{4}$-DPA NPs were added. The mixtures were shaken on a shaker for $10 \mathrm{~min}$ and magnetic adsorbents were collected utilizing the magnetic bead separation system "Dynamag TM-15". Finally, $2 \mathrm{~mL}$ of desorption solvents were added into each Falcon tube containing collected MNPs. The mixtures were shaken for $10 \mathrm{~min}$. Thereafter, magnetic adsorbents were re-collected employing the Invitrogen magnetic bead separation system and $100 \mu \mathrm{L}$ of supernatants were injected into HPLC for analysis.

\section{Calibration curve}

Because the best solution for retrieving was acetonitrile:water:acetic acid $(99: 99: 2 \mathrm{v} / \mathrm{v} / \mathrm{v})$; so, to draw a calibration curve for HPLC analysis, six standard concentrations of ochratoxin A $(1,5,10,15,20$ and $30 \mathrm{ng} \mathrm{mL}^{-1}$ ) were prepared in the mobile phase and $100 \mu \mathrm{L}$ were injected into HPLC instrument $\left(\mathrm{R}^{2}=0.9954\right)$. The 
limit of detection (LOD) was calculated according to the standard deviation of blank $\left(\mathrm{S}_{\mathrm{b}}\right)$ and slope of calibration curve $(\mathrm{m})$ according to equation 1.

$\mathrm{LOD}=\frac{3 \mathrm{~S}_{\mathrm{b}}}{\mathrm{m}}$

On the other hand, to draw a calibration curve for fluorescence spectroscopy, six concentrations were prepared in the acetonitrile:methanol $(80: 20 \mathrm{v} / \mathrm{v})$ at $\mathrm{pH}=5$ (best extraction solvent) and fluorescence intensity of these solutions were measured at 334 and $451 \mathrm{~nm}\left(\mathrm{R}^{2}=0.9973\right)$.

\section{Results and Discussion}

\section{Synthesis and characterization}

The surface-modified MNPs, due to the high surface area and high sorption ability, have been widely utilized as adsorbent particles with greater stability in different media. ${ }^{21,22}$ Accordingly, the synthesis of $\mathrm{Fe}_{3} \mathrm{O}_{4}$-DPA NPs was initiated through the synthesis of $\mathrm{Fe}_{3} \mathrm{O}_{4}$, the core of NPs, at $270{ }^{\circ} \mathrm{C}$ by thermal decomposition reaction of $\mathrm{Fe}(\mathrm{acac})_{3}$ in the presence of oleylamine as a reducing, capping, and monodisperse agent. ${ }^{23-25}$ Surface of MNPs (ca. 7-10 nm) was modified by dopamine hydrobromide (DPA), a robust anchoring molecule, to substitute the oleylamine on the surface of $\mathrm{Fe}_{3} \mathrm{O}_{4}$ NPs. ${ }^{26}$ This step was confirmed with FTIR spectrum utilizing Shimadzu IR PRESTIGE 21 spectrophotometer. The main absorption peaks in the FTIR spectrum (Figure 2) of $\mathrm{Fe}_{3} \mathrm{O}_{4}$-DPA NPs are: $v_{\max }=1430$ and $3435 \mathrm{~cm}^{-1}$, which confirm the availability of $\mathrm{NH}_{2}$ at the end of the structure of the $\mathrm{Fe}_{3} \mathrm{O}_{4}-\mathrm{DPA}, \mathrm{v}_{\max }=630$, $588,442 \mathrm{~cm}^{-1}$ corroborate the $\mathrm{Fe}-\mathrm{O}$ bond of $\mathrm{Fe}_{3} \mathrm{O}_{4}$ and $v_{\max }=1630 \mathrm{~cm}^{-1}$ clearly indicates the aromatic structure of dopamine modified $\mathrm{Fe}_{3} \mathrm{O}_{4}$.

According to DLS analysis, the size of $\mathrm{Fe}_{3} \mathrm{O}_{4}$ and $\mathrm{Fe}_{3} \mathrm{O}_{4}$-DPA NPs were 7-10 and 13-16 nm, respectively (Figures 3A and 3B). The dopamine-coated magnetic nanoparticles had a zeta potential value of $16.8 \mathrm{mV}$, this characteristic makes them to be freely dispersed in fluids without aggregations. On the other hand, being positively charged can help in the extraction properties of $\mathrm{Fe}_{3} \mathrm{O}_{4}$-DPA NPs. ${ }^{13}$

The FESEM and TEM micrographs specified the morphological characteristics and the size of $\mathrm{Fe}_{3} \mathrm{O}_{4}$-DPA NPs. Size of this product is about $15 \mathrm{~nm}$ (Figures 1C and 1D). Changes in the size and morphology of MNPs confirmed the successful engineering of DPA-conjugated MNPs.

VSM analysis (hysteresis curve and zero magnetic remanence) at room temperature shows that $\mathrm{Fe}_{3} \mathrm{O}_{4}$-DPA NPs are superparamagnetic. Figures $3 \mathrm{C}$ and $3 \mathrm{D}$ illustrate the magnetic momentum of this product. The saturation magnetization $\mathrm{MS}$ at $300 \mathrm{~K}$ is $40 \mathrm{emu} \mathrm{g}^{-1}$, which is

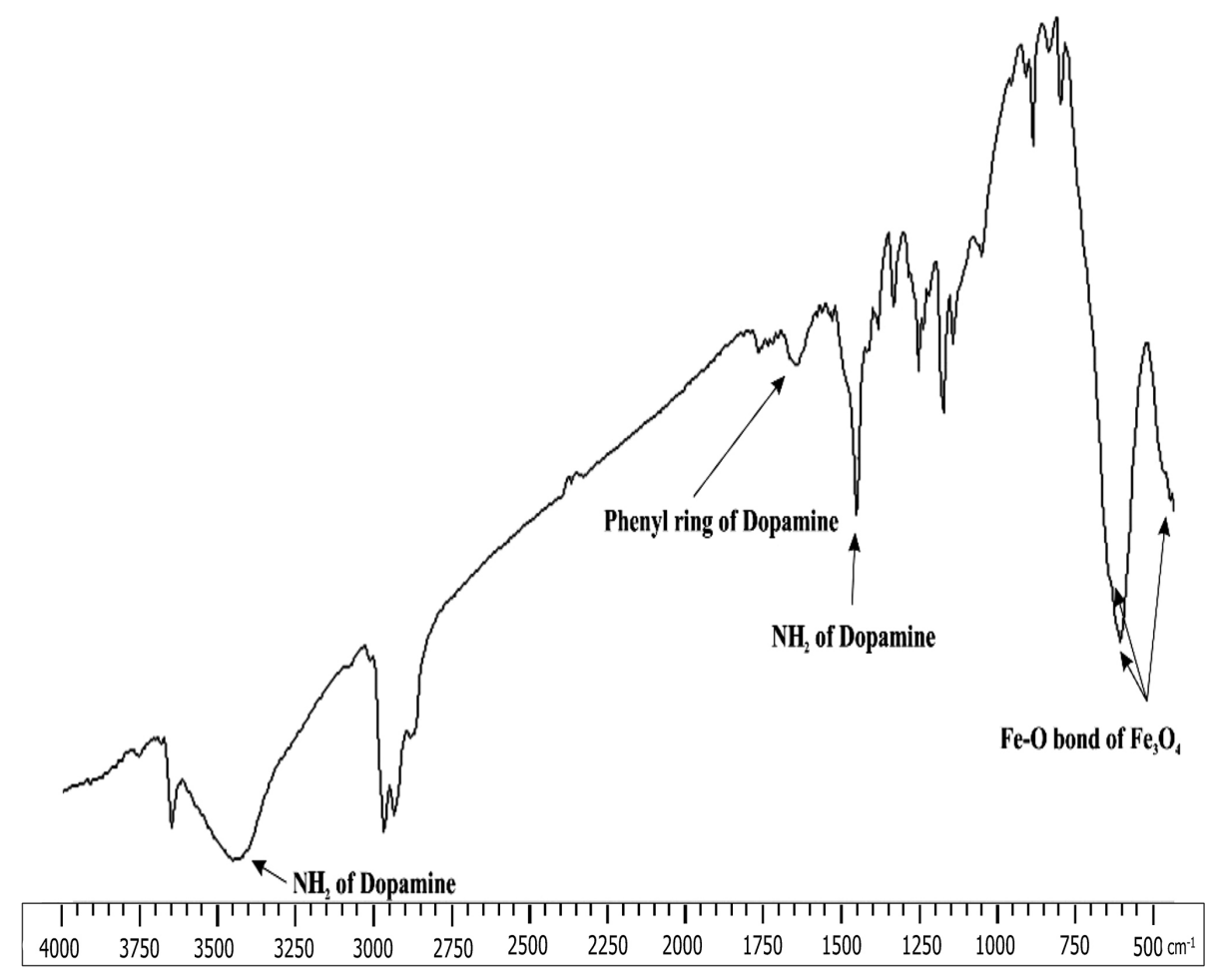

Figure 2. FTIR spectra of $\mathrm{Fe}_{3} \mathrm{O}_{4}$-DPA NPs. Absorption at $1630 \mathrm{~cm}^{-1}$ clearly indicates the aromatic structure of dopamine modify $\mathrm{Fe}_{3} \mathrm{O}_{4}$. 

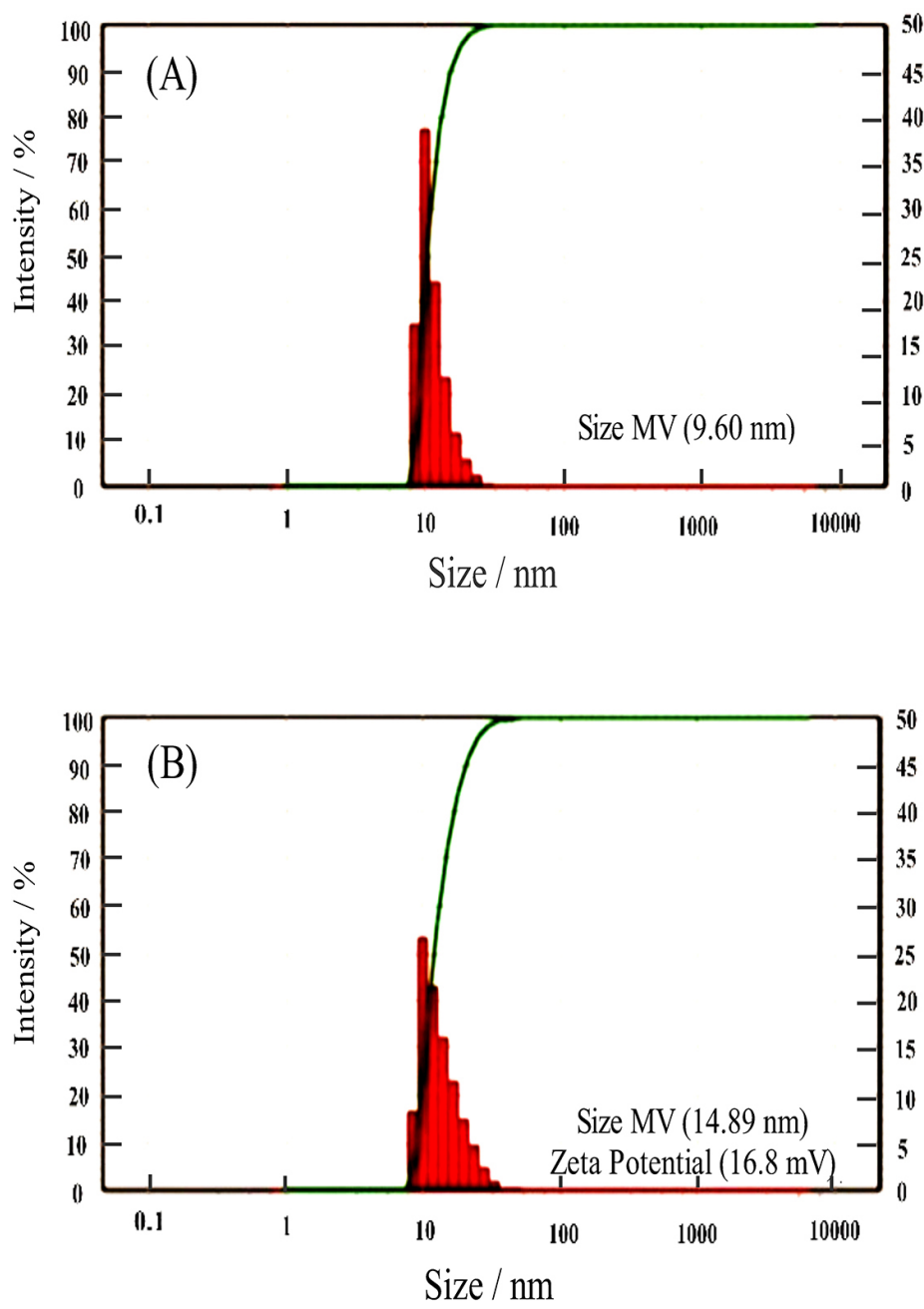
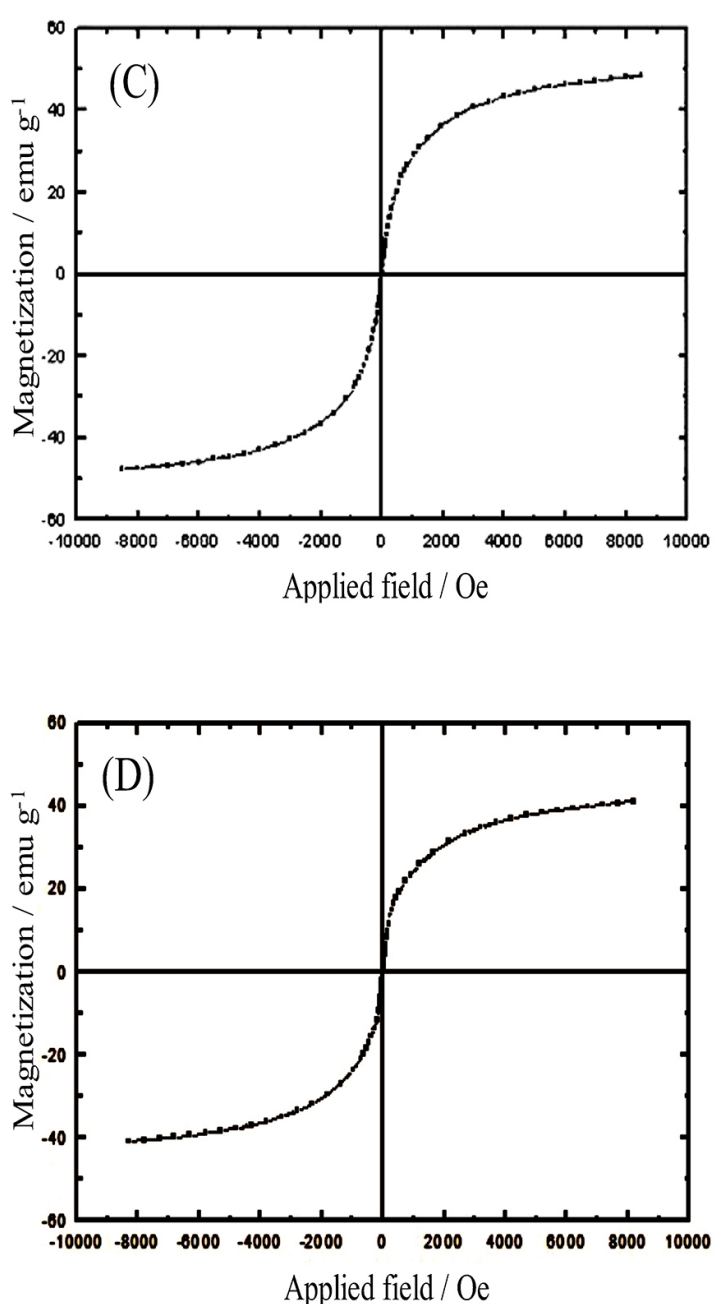

Figure 3. (A) DLS image of $\mathrm{Fe}_{3} \mathrm{O}_{4} \mathrm{NPs}$ and (B) DLS image of $\mathrm{Fe}_{3} \mathrm{O}_{4}$-DPA NPs; (C) magnetic momentum of Fe $\mathrm{O}_{4}$ NPs and (D) magnetic momentum of $\mathrm{Fe}_{3} \mathrm{O}_{4}$-DPA NPs.

significantly less than that of the bare MNPs. ${ }^{25}$ The reduction in magnetization could be due to surface modification of $\mathrm{Fe}_{3} \mathrm{O}_{4}$ with DPA.

\section{HPLC analysis for MSPE from solvents}

This test is useful for finding best solvents for high extraction of ochratoxin A from real samples, because solvents play a key role in the extraction procedure. For instance, solvents are miscible with the sample matrix in order to improve the extraction efficiency of samples and also enhance the retrieval rate of samples. ${ }^{27}$ Moreover, in validated methods, solvents are useful in clean-up process of OTA, because in HPLC method, clean-up is necessary to protect the column and also to obtain low detection limits. ${ }^{7}$ Accordingly, ochratoxin A solutions were prepared in different solvents and $\mathrm{Fe}_{3} \mathrm{O}_{4}$-DPA NPs were thereafter added to them. In each extraction, ochratoxin A was retrieved from the MNPs with variable desorption solvents and was quantified with HPLC method. Multiple HPLC method has been reported for ochratoxin A evaluation. In the present study, acetonitrile:water:acetic acid was selected as mobile phase with flow rate of $1.5 \mathrm{~mL} \mathrm{~min}{ }^{-1}$. With a $\mathrm{C} 18$ column, ochratoxin A was detected within 2.5-3.5 min. ${ }^{6,28}$ Theoretically sorbent (MNPs) and sample (OTA) can interact with both electrostatic interactions and hydrophobic moieties, for the reason that in normal condition (without $\mathrm{pH}$-modifying), OTA exists in anionic form (OTA) and $\mathrm{Fe}_{3} \mathrm{O}_{4}$-DPA NPs have positively charged amine $\left(-\mathrm{NH}_{3}{ }^{+}\right){ }^{6,7,20,29}$ Trials in this condition showed that, the best solvent for extraction was acetonitrile:methanol $(80: 20 \mathrm{v} / \mathrm{v})$ and the best desorption solvent was acetonitrile:water:acetic acid (99:99:2 v/v/v). Pre-extraction analysis of ochratoxin A confirmed the miscibility and existence of OTA in acetonitrile:methanol (80:20 v/v) (Figure 4A).

In the extraction of the target analytes (for example OTA), it is important that solvents don't interfere in the 
(A)

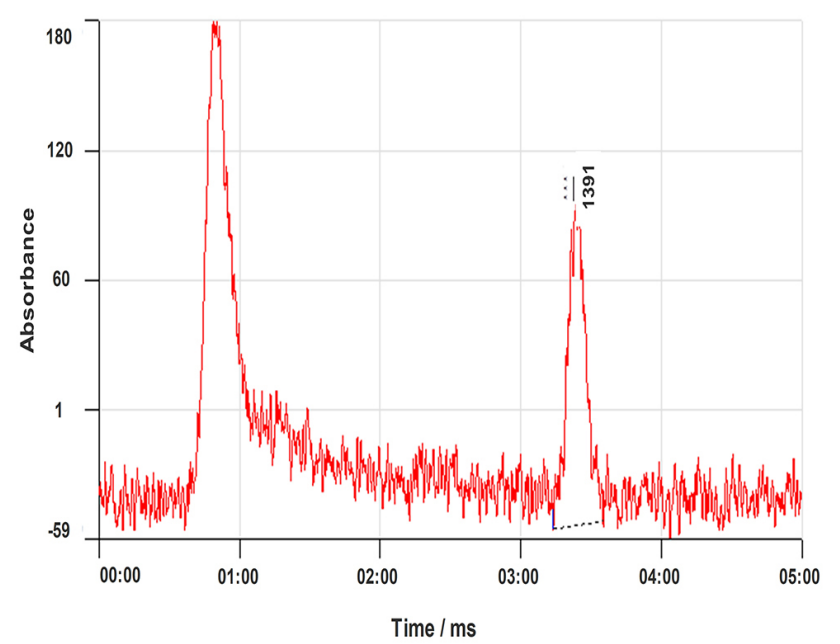

(B)

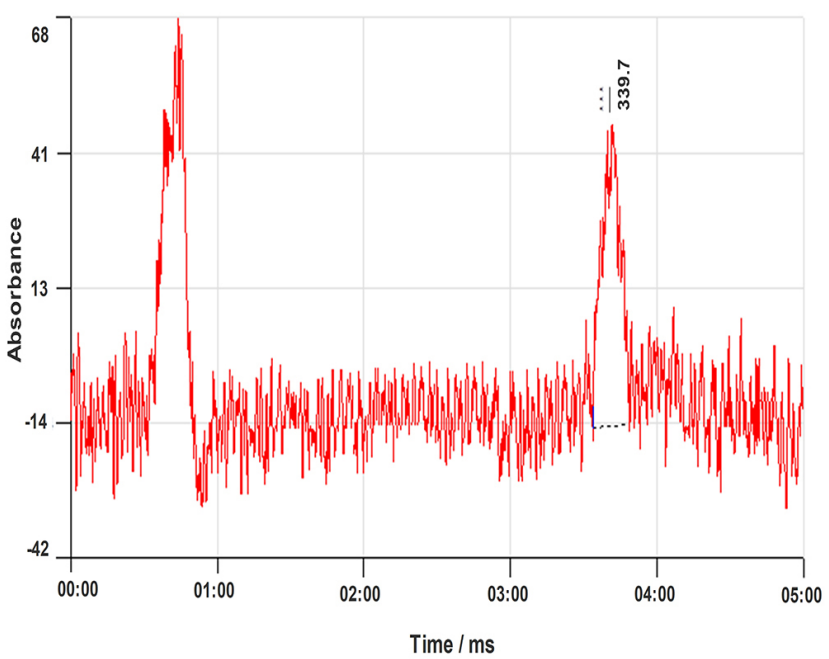

(C)

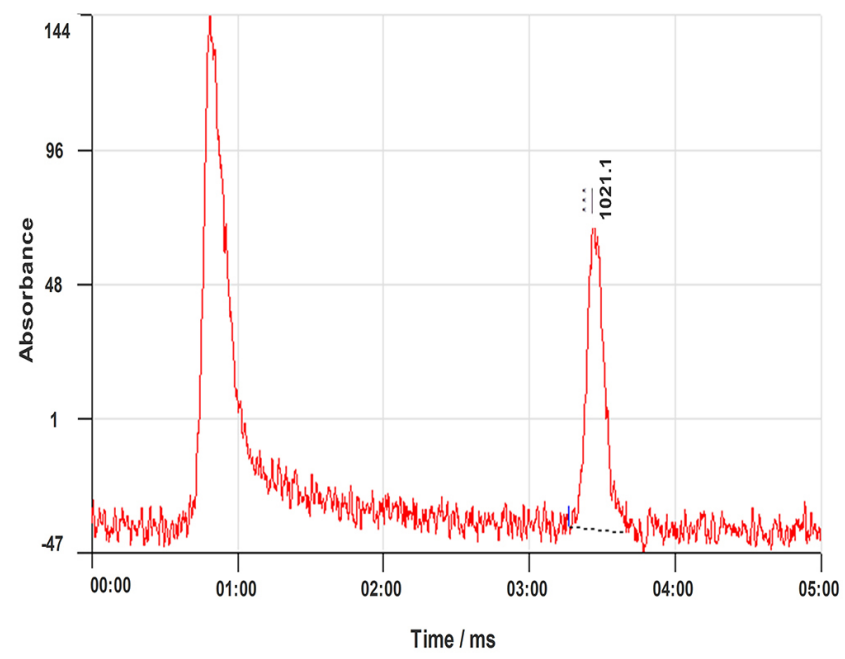

Figure 4. (A) Pre-extraction analysis of ochratoxin A in acetonitrile:methanol solution (10 $\mathrm{ng} \mathrm{mL}^{-1}$ of OTA) by HPLC. Existence and miscibility of OTA in extraction solvent was confirmed; (B) extraction of ochratoxin A with $30 \mathrm{ng}$ of $\mathrm{Fe}_{3} \mathrm{O}_{4}$-DPA NPs from acetonitrile:methanol solution (the area under the peak related to OTA (RT = 03:41) has decreased); (C) ochratoxin A desorption from $\mathrm{Fe}_{3} \mathrm{O}_{4}$-DPA NPs by acetonitrile:water:acetic acid solution (retrieved percentage \pm RSD ca. $70.6 \pm 4.5 \%)(n=3)$.

extraction procedure, and also could help to increase the extraction rate. ${ }^{27}$ After separation of MNPs from solvent, injection of extraction supernatant into HPLC showed that the high percentage of OTA in acetonitrile:methanol (80:20 v/v) was adsorbed on MNPs. The related peak to ochratoxin A has reduced when compared to the HPLC spectra of pre-extraction analysis (Figure 4B).

After retrieving the OTA from $\mathrm{Fe}_{3} \mathrm{O}_{4}$-DPA NPs via different desorption solvents, the recovery percentage of OTA from all extraction solvents were calculated through the following equation.

Recovery $(\%)=\left(\frac{\text { measured concentration }}{\text { nominal concentration }}\right) \times 100$
According to Table 1, almost $71 \%$ of ochratoxin A was retrieved from the $\mathrm{Fe}_{3} \mathrm{O}_{4}$-DPA nanoparticles utilizing the acetonitrile:water:acetic acid (99:99:2 v/v/v), as the best desorption solvent. Figure 4C illustrates the HPLC spectra of retrieved OTA by acetonitrile:water:acetic acid ( $\mathrm{R}=71 \%$ ). The $\mathrm{LOD}$ value was $0.02 \mathrm{ng} \mathrm{mL}^{-1}$ where the calibration equation was $\mathrm{y}=64.636 \mathrm{x}+51.249$.

\section{Effect of sorbent and desorption time}

Using an external magnetic field, MNPs can minimize the extraction time of ochratoxin $\mathrm{A} \cdot{ }^{30}$ Therefore, the effects of $\mathrm{Fe}_{3} \mathrm{O}_{4}$-DPA NPs on adsorption of ochratoxin A were evaluated. Different amounts of MNPs were selected in the 
Table 1. Percent recovery of ochratoxin A $\left(10 \mathrm{ng} \mathrm{mL}^{-1}\right)$ from different solvents. Ochratoxin A was extracted from different solvents and was retrieved by three desorption solvents

\begin{tabular}{|c|c|c|c|c|}
\hline \multirow[b]{2}{*}{ Extraction solvent } & \multirow[b]{2}{*}{ Ratio / \% } & \multicolumn{3}{|c|}{ Extraction with different desorption solvents (recovery \pm RSD $/ \%, \mathrm{n}=3$ ) } \\
\hline & & $\begin{array}{c}\text { Ethyl acetate:methanol } \\
50: 50\end{array}$ & $\begin{array}{c}\text { Thiourea } \\
100\end{array}$ & $\begin{array}{c}\text { Water:acetonitrile:acetic acid } \\
49.5: 49.5: 1\end{array}$ \\
\hline Hexane & 100 & $11.2 \pm 6.7$ & $22.4 \pm 5.1$ & $41.6 \pm 3.4$ \\
\hline 2-Pentanol & 100 & $22.3 \pm 3.6$ & $18.7 \pm 6.0$ & $33.5 \pm 8.2$ \\
\hline 2-Propanol & 100 & $22.5 \pm 5.9$ & $19.7 \pm 2.5$ & $38.1 \pm 1.5$ \\
\hline Water & 100 & $18.5 \pm 12.3$ & $12.1 \pm 5.2$ & $19.7 \pm 7.4$ \\
\hline Acetonitrile & 100 & $34.6 \pm 4.4$ & $32.0 \pm 2.8$ & $55.6 \pm 1.2$ \\
\hline Methanol & 100 & $17.8 \pm 7.2$ & $17.9 \pm 3.8$ & $26.8 \pm 2.5$ \\
\hline Petroleum ether & 100 & $31.7 \pm 1.9$ & $21.0 \pm 4.6$ & $44.8 \pm 4.5$ \\
\hline Ethyl acetate & 100 & $26.6 \pm 1.5$ & $8.7 \pm 3.7$ & $40.1 \pm 9.5$ \\
\hline Acetonitrile:2-pentanol & $50: 50$ & $23.6 \pm 10.2$ & $31.3 \pm 4.6$ & $49.9 \pm 5.6$ \\
\hline Acetonitrile:2-pentanol & $20: 80$ & $12.9 \pm 1.9$ & $29.4 \pm 9.0$ & $48.6 \pm 5.9$ \\
\hline Acetonitrile:2-pentanol & $80: 20$ & $31.3 \pm 11.1$ & $33.1 \pm 1.2$ & $62.9 \pm 3.2$ \\
\hline Acetonitrile:methanol & $50: 50$ & $32.1 \pm 2.3$ & $21.8 \pm 2.2$ & $67.8 \pm 14.3$ \\
\hline Acetonitrile:methanol & $20: 80$ & $31.5 \pm 5.6$ & $16.9 \pm 8.9$ & $45.1 \pm 1.1$ \\
\hline Acetonitrile:methanol & $80: 20$ & $34.6 \pm 2.5$ & $31.1 \pm 9.1$ & $70.6 \pm 4.5$ \\
\hline Hexane:acetonitrile & $50: 50$ & $43.6 \pm 3.4$ & $21.4 \pm 3.3$ & $56.9 \pm 6.7$ \\
\hline Hexane:acetonitrile & $20: 80$ & $41.6 \pm 4.6$ & $22.2 \pm 2.2$ & $59.8 \pm 11.3$ \\
\hline Hexane:acetonitrile & $80: 20$ & $44.5 \pm 9.3$ & $20.8 \pm 2.4$ & $42.8 \pm 1.4$ \\
\hline Water:methanol & $50: 50$ & $11.9 \pm 5.6$ & $6.9 \pm 13.4$ & $15.0 \pm 3.3$ \\
\hline Water:methanol & $20: 80$ & $12.3 \pm 1.8$ & $8.0 \pm 9.9$ & $19.3 \pm 2.9$ \\
\hline Water:methanol & $80: 20$ & $10.8 \pm 12.0$ & $7.9 \pm 2.1$ & $17.9 \pm 8.3$ \\
\hline
\end{tabular}

range of 5-50 ng and were added to micro tubes containing $10 \mathrm{ng} \mathrm{mL}^{-1}$ of ochratoxin A ( $\left.2 \mathrm{~mL}\right)$. The HPLC analysis of these tests indicated that extraction efficiency was increased with increase in MNPs and remained constant at $30 \mathrm{ng}$ (Figure 5A).

Moreover, the extraction and desorption processes were tested by magnetic stirring at three different times: 10, 20 and $30 \mathrm{~min}$. The HPLC results confirmed that there was no significant difference between these times.

\section{Effect of $\mathrm{pH}$}

In OTA, the carboxyl group of the phenylalanine part (pKa ca. 4.4) and the phenolic hydroxyl group of the isocoumarin part (pKa ca. 7.3) have weak acidic properties. ${ }^{31}$ On the other hand, in DPA, amino group (pKa ca. 9.1) has basic properties. ${ }^{32}$ According to $\mathrm{pH}$-partition theory, bases become positive in acidic solutions when the $\mathrm{pH}$ values are below the $\mathrm{pKa}$, and acids become negative in basic solutions when the $\mathrm{pH}$ values are above the $\mathrm{pKa} .{ }^{33}$ Therefore, the effect of $\mathrm{pH}$ is remarkable and effective on the extent of adsorption from a solution. Considering the pKa value of OTA and the amino group at the end of
$\mathrm{Fe}_{3} \mathrm{O}_{4}$-DPA NPs, five $\mathrm{pH}$ for the best extraction solvent were adjusted $(\mathrm{pH}=5.0-9.0)$. The best $\mathrm{pH}$ was 5.0, because nearly $94 \%$ of ochratoxin A was adsorbed on $\mathrm{Fe}_{3} \mathrm{O}_{4}$-DPA NPs; as anticipated. Because at this pH, OTA is in monoanionic form and DPA is in the highest cationic form. The Henderson-Hasselbalch equations ${ }^{34}$ are utilized to describe the ionization of weak acid and weak base in chemical systems:

For weak acid: $\mathrm{pH}-\mathrm{pK}_{\mathrm{a}}=\log \frac{\left[\mathrm{A}^{-}\right]_{\text {Ionized form }}}{[\mathrm{HA}]_{\text {Un-ionized form }}}$

For weak base: $\mathrm{pK}_{\mathrm{a}}-\mathrm{pH}=\log \frac{\left[\mathrm{BH}^{+}\right]_{\text {Ionized form }}}{[\mathrm{B}]_{\text {Un-ionized form }}}$

On the other hand, increasing the $\mathrm{pH}$ of the extraction solutions reduced the adsorption of OTA to nanoparticle. Because the increase of $\mathrm{pH}$ reduces the cationic form of amine, therefore, the lowest adsorption was occurred at $\mathrm{pH}=9$. Figure 5B shows the results of these tests.

The best solvent for desorption was acetonitrile: water:acetic acid ( $\mathrm{pH}$ ca. 3.3), ${ }^{7,35}$ because we suspected that at this $\mathrm{pH}$ ochratoxin $\mathrm{A}$ is in un-ionized form and also 

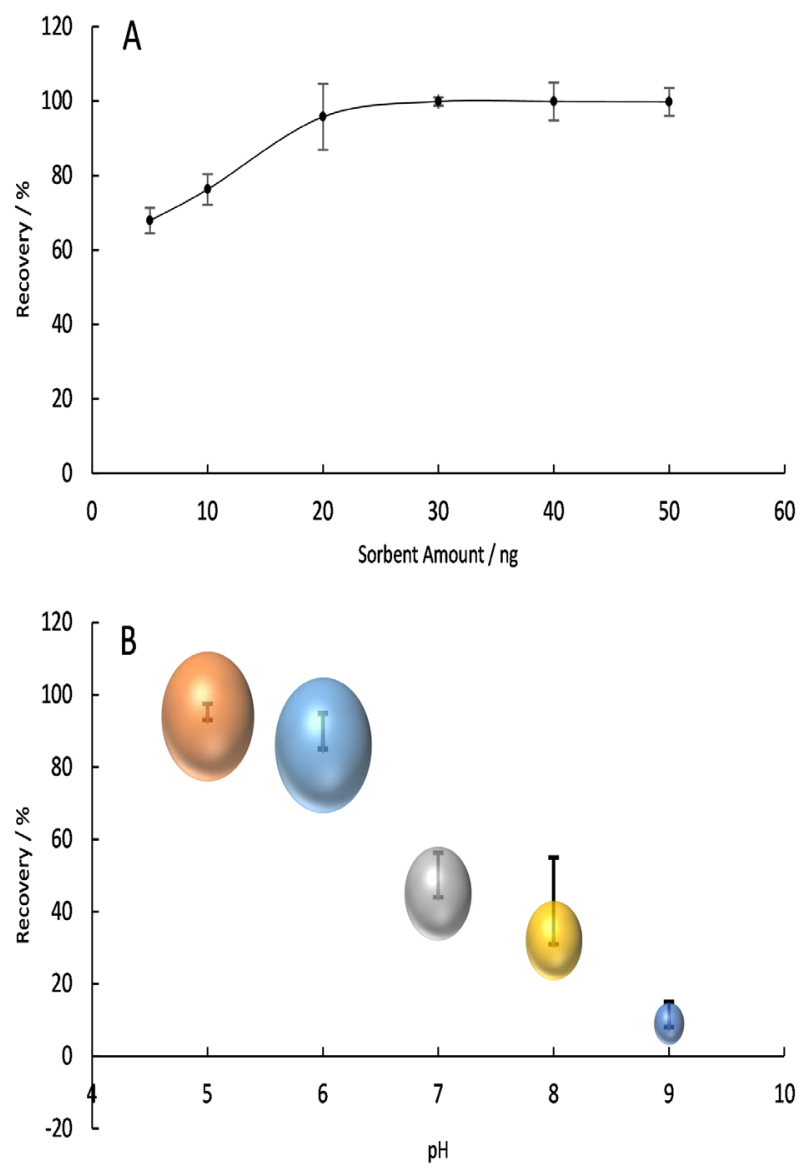

Figure 5. (A) Effect of adsorbent amount on extraction efficiency. Extraction efficiency remained constant in the $30 \mathrm{ng}(\mathrm{n}=5)$; (B) five $\mathrm{pH}$ for the best extraction solvent and their extraction rate. By increasing the $\mathrm{pH}$, the recovery percentage has decreased $(\mathrm{n}=3)$.

the amine group of dopamine can interact with acetic acid to form acetate salt.

\section{Fluorescence spectroscopy}

The aim of fluorescence spectroscopy was to determine the ability of $\mathrm{Fe}_{3} \mathrm{O}_{4}$-DPA NPs to provide acceptable interaction with ochratoxin A. Regarding the above results, acetonitrile:methanol $(80: 20 \mathrm{v} / \mathrm{v})$ and $\mathrm{pH}=5$ was selected as best extraction solvent. So, fluorescence excitation spectra of OTA $\left(10 \mathrm{ng} \mathrm{mL}^{-1}\right)$ before and after extraction with MNPs were taken in this condition. As illustrated in Figure 6, the fluorescence intensity of ochratoxin A was reduced after extraction by $\mathrm{Fe}_{3} \mathrm{O}_{4}$-DPA NPs (extraction percentage was $89 \%$ ). This study also found that $\mathrm{Fe}_{3} \mathrm{O}_{4}$-DPA NPs were able to extract OTA from solutions.

\section{Analysis of real sample}

The OTA found in milk, can be carcinogenic to humans. The European Commission has recommended a Provisional

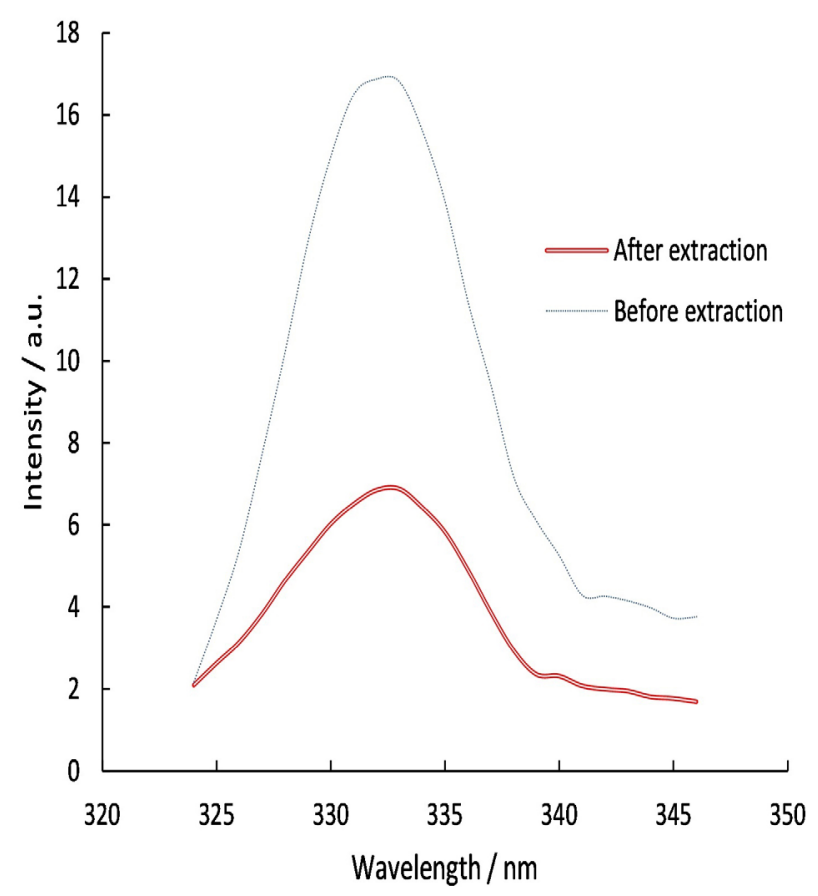

Figure 6. Fluorescence excitation spectra of ochratoxin A. The fluorescence intensity of OTA decreased after extraction with $30 \mathrm{ng}$ of $\mathrm{Fe}_{3} \mathrm{O}_{4}$-DPA NPs. Excitation spectra were obtained by scanning at 324-346 nm.

Tolerable Weekly Intake (PTWI) of $120 \mathrm{ng}$ per $\mathrm{kg}$ for OTA. ${ }^{36}$ Thus, the MSPE was carried out to evaluate the method for extraction of ochratoxin A from milk, because this method is simpler and requires less time. ${ }^{37}$

Recovery percentages were evaluated by spiking the milk with different amounts of OTA, when the solvents of the previous step were used. The results in Figure 7 show that the recovery values were in the range of 43.4-67.8\%. Moreover, the results show that the effects of sample matrices such as organic acids and lipids are small, because there is little difference between percent recovery from real sample and percent recovery from organic solvents.

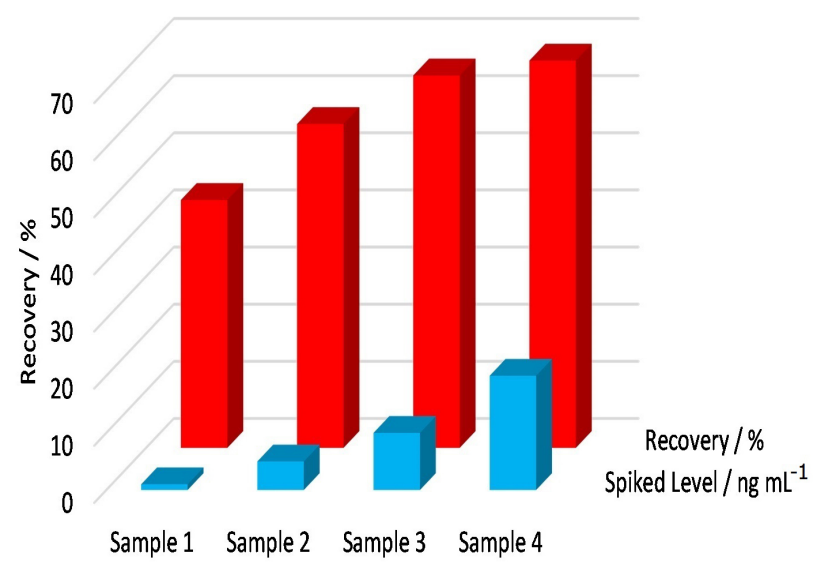

Figure 7. Percent recovery for spiked milk with different amount of ochratoxin A $(n=5)$. 


\section{Conclusions}

MNPs have great potential to be utilized for solid phase extraction. Although in recent decade, efforts were made for the extraction of ochratoxin A with magnetic nanoparticles, in this work, for the first time, we implemented a very simple and fast method for extraction of OTA from solutions by MNPs. Accordingly, magnetic adsorbents were prepared by conjugation of dopamine to $\mathrm{Fe}_{3} \mathrm{O}_{4}$ nanoparticles. For the detection of OTA which is also for the first time, we utilized HPLC and fluorescence spectroscopy systems together. Both confirmed the ability of $\mathrm{Fe}_{3} \mathrm{O}_{4}$-DPA NPs to extract the OTA from solvents and milk. Moreover, by adjusting the $\mathrm{pH}$, we could improve extraction percentage. Based on our findings and good recoveries for spiked milk samples, we propose that $\mathrm{Fe}_{3} \mathrm{O}_{4}$-DPA NPs can reduce the extraction time and cost for the extraction of ochratoxin A and we hope that in the future, it can be used for real samples.

\section{Acknowledgments}

This article has been extracted from student research projects that has been supported by Student Research Committee of Zabol University of Medical Sciences. The authors thank for all support provided.

\section{References}

1. Wang, C.; Qian, J.; Wang, K.; Liu, Q.; Dong, X.; Huang, X.; Biosens. Bioelectron. 2015, 68, 783.

2. Mariño-Repizo, L.; Kero, F.; Vandell, V.; Senior, A.; SanzFerramola, M. I.; Cerutti, S.; Raba, J.; Food Chem. 2015, 172, 663.

3. Li, S.; Marquardt, R. R.; Frohlich, A. A.; Vitti, T. G.; Crow, G.; Toxicol. Appl. Pharmacol. 1997, 145, 82.

4. Welke, J. E.; Hoeltz, M.; Dottori, H. A.; Noll, I. B.; J. Braz. Chem. Soc. 2010, 21, 441.

5. Almeda, S.; Arce, L.; Valcárcel, M.; Electrophoresis 2008, 29, 1573.

6. Mashhadizadeh, M. H.; Amoli-Diva, M.; Pourghazi, K.; J. Chromatogr. A 2013, 13, 17 .

7. González-Peñas, E.; Leache, C.; Viscarret, M.; De Obanos, A. P.; Araguás, C.; De Cerain, A. L.; J. Chromatogr. A 2004, 1025, 163.

8. Hackbart, H.; Prietto, L.; Primel, E. G.; Garda-Buffon, J.; Badiale-Furlong, E.; J. Braz. Chem. Soc. 2012, 23, 103.

9. Bansal, J.; Pantazopoulos, P.; Tam, J.; Cavlovic, P.; Kwong, K.; Turcotte, A.-M.; Lau, B.-Y.; Scott, P.; Food Addit. Contam. 2011, 28, 767 .

10. Tabrizi, A. B.; Rashidi, M. R.; Ostadi, H.; J. Braz. Chem. Soc. 2014, 25, 709 .
11. Hashemi, M.; Taherimaslak, Z.; Rashidi, S.; Spectrochim. Acta Part A 2014, 128, 583.

12. Ahn, S.; Lee, S.; Lee, J.; Kim, B.; Food Chem. 2016, 190, 368.

13. Poor, M.; Kunsagi-Mate, S.; Szente, L.; Matisz, G.; Secenji, G.; Czibulya, Z.; Koszegi, T.; Food Chem. 2015, 172, 143.

14. Heidari Majd, M.; Akbarzadeh, A.; Sargazi, A. Artif. Cells, Nanomed., Biotechnol. 2016, DOI 10.3109/21691401.2016.1160916.

15. Majd, M. H.; Barar, J.; Asgari, D.; Valizadeh, H.; Rashidi, M. R.; Kafil, V.; Shahbazi, J.; Omidi, Y.; Adv. Pharm. Bull. 2013, 3,189 .

16. McCullum, C.; Tchounwou, P.; Ding, L. S.; Liao, X.; Liu, Y. M.; J. Agric. Food Chem. 2014, 62, 4261.

17. Saei, A.; Barzegari, A.; Majd, M.; Asgari, D.; Omidi, Y.; J. Nanopart. Res. 2014, 16, 1.

18. Sargazi, A.; Kuhestani, K.; Nahoki, T. N.; Heidari Majd, M.; Int. J. Pharm. Sci. Res. 2015, 6, 5047.

19. Barar, J.; Kafil, V.; Majd, M. H.; Barzegari, A.; Khani, S.; JohariAhar, M.; Asgari, D.; Cokous, G.; Omidi, Y.; J. Nanobiotechnol. 2015, 13, 1 .

20. Poor, M.; Kunsagi-Mate, S.; Szente, L.; Matisz, G.; Secenji, G.; Czibulya, Z.; Koszegi, T.; Food Chem. 2015, 172, 143.

21. Wierucka, M.; Biziuk, M.; TrAC, Trends Anal. Chem. 2014, 59, 50.

22. Giakisikli, G.; Anthemidis, A. N.; Anal. Chim. Acta 2013, 789, 1

23. Wang, B.; Xu, C.; Xie, J.; Yang, Z.; Sun, S.; J. Am. Chem. Soc. 2008, 130, 14436.

24. Xu, Z.; Shen, C.; Hou, Y.; Gao, H.; Sun, S.; Chem. Mater. 2009, $21,1778$.

25. Heidari Majd, M.; Asgari, D.; Barar, J.; Valizadeh, H.; Kafil, V.; Coukos, G.; Omidi, Y.; J. Drug Targeting 2013, 21, 328.

26. Xu, C.; Xu, K.; Gu, H.; Zheng, R.; Liu, H.; Zhang, X.; Guo, Z.; Xu, B.; J. Am. Chem. Soc. 2004, 126, 9938.

27. Behbahani, M.; Ghareh Hassanlou, P.; Amini, M. M.; Omidi, F.; Esrafili, A.; Farzadkia, M.; Bagheri, A.; Food Chem. 2015, $187,82$.

28. Serra, R.; Mendonça, C.; Abrunhosa, L. s.; Pietri, A.; Venâncio, A.; Anal. Chim. Acta 2004, 513, 41.

29. Teixeira, T. R.; Hoeltz, M.; Einloft, T. C.; Dottori, H. A.; Manfroi, V.; Noll, I. B.; Food Addit. Contam., Part B 2011, 4, 289.

30. Ibarra, I. S.; Miranda, J. M.; Rodriguez, J. A.; Nebot, C.; Cepeda, A.; Food Chem. 2014, 157, 511.

31. Anli, E.; Alkis, İ. M.; J. Inst. Brew. 2010, 116, 23.

32. Korpany, K. V.; Habib, F.; Murugesu, M.; Blum, A. S.; Mater. Chem. Phys. 2013, 138, 29.

33. Shore, P. A.; Brodie, B. B.; Hogben, C. A.; J. Pharmacol. Exp. Ther. 1957, 119, 361

34. Po, H. N.; Senozan, N.; J. Chem. Educ. 2001, 78, 1499. 
35. Fujii, S.; Ono, E. Y. S.; Ribeiro, R. M. R.; Assunção, F. G. A.; Takabayashi, C. R.; Oliveira, T. C. R. M.; Itano, E. N.; Ueno, Y.; Kawamura, O.; Hirooka, E. Y.; Braz. Arch. Biol. Technol. 2007, 50, 349.

36. Flores-Flores, M. E.; Lizarraga, E.; López de Cerain, A.; González-Peñas, E.; Food Control 2015, 53, 163.
37. Taherimaslak, Z.; Amoli-Diva, M.; Allahyary, M.; Pourghazi, K.; Anal. Chim. Acta 2014, 842, 63.

Submitted: February 4, 2016

Published online: August 30, 2016 